14

\title{
Исследование электрофизических свойств композиционных волокон на основе хитозана и полипиррола для тканевой инженерии
}

\author{
(C) П.А. Алешин, ${ }^{1}$ А.Н. Алешин, ${ }^{1}$ Е.Ю. Розова, ${ }^{2,3}$ Е.Н. Дресвянина, ${ }^{3,4}$ Н.Н. Сапрыкина, ${ }^{2}$ В.Е. Юдин ${ }^{2,3}$ \\ ${ }^{1}$ Физико-технический институт им. А.Ф. Иофрфе РАН, \\ 194021 Санкт-Петербург, Россия \\ ${ }^{2}$ Институт высокомолекулярных соединений, \\ 199004 Санкт-Петербург, Россия \\ ${ }^{3}$ Санкт-Петербургский политехнический университет Петра Великого, \\ 195251 Санкт-Петербург, Россия \\ ${ }^{4}$ Санкт-Петербургский государственный университет промышленных технологий и дизайна, \\ 191186 Санкт-Петербург, Россия \\ e-mail: aleshin@transport.ioffe.ru
}

Поступило в Редакцию 13 мая 2021 г.

В окончательной редакции 16 июня 2021 г.

Принято к публикации 20 июня 2021 г.

\begin{abstract}
Получены композиционные волокна на основе хитозана, покрытые проводящим полимером полипирролом (ППир). Методом сканирующей электронной микроскопии исследована их морфология. Оценена электропроводность волокон в сухом состоянии и в жидкой культуральной среде, имитирующей тканевую жидкость. Определены значения удельного сопротивления $\rho$ и проводимости $\sigma$ исследуемых волокон в зависимости от количества слоев ППир, степени вытяжки (ориентации) волокон в сухой и в жидкой средах. Установлено, что с увеличением величины фильерной вытяжки от 0 до $100 \% \rho$ волокон падает как в сухом состоянии, так и в жидкой культуральной среде. При этом максимальное падение $\rho$ волокон при погружении в жидкую культуральную среду наблюдалось для невытянутых волокон с двумя слоями ППир. Показано, что после начального падения $\rho$ ориентированных волокон хитозана с одним и двумя слоями ППир $\rho$ слабо меняется в жидкой культуральной среде в течение $2 \mathrm{~h}$. Исследованные ориентированные полимерные волокна хитозана, покрытые одним и двумя слоями ППир, перспективны для использования в области тканевой инженерии и регенеративной медицины.
\end{abstract}

Ключевые слова: волокна хитозана, проводящие полимеры, электропроводность, тканевая инженерия.

DOI: 10.21883/JTF.2021.11.51545.143-21

\section{Введение}

В последние годы природный полимер хитозан (линейный полисахарид), обладающий высокой биосовместимостью, низкой токсичностью и биоразлагаемостью, а также композиты на его основе, модифицированные проводящими полимерами, активно исследуются как потенциальные биоматериалы для биомедицинских и биоинженерных применений [1-3]. Одним из наиболее перспективных направлений в этой области исследований является разработка нейроморфных устройств на основе нейроморфных чипов - процессоров, работа которых основана на принципах функционирования человеческого мозга. Системам искусственного интеллекта на базе этой технологии нет необходимости обращаться к массивному сетевому хранилищу данных, так как вся информация содержится в искусственных нейронах [4]. В этой связи считывание информации с помощью биосовместимых низкоразмерных полимерных проводов является важной задачей в этой области исследований [5]. Электропроводящие свойства волокон хитозана исследовались в последние годы достаточно интенсивно, но, как правило, только при нормальных условиях, т.е. в сухом состоянии при $290 \mathrm{~K}$ [6]. Однако электрические свойства волокон хитозана, покрытых проводящим полимером, погруженных в жидкую культуральную среду, моделирующую тканевую среду, до настоящего времени не были исследованы достаточно подробно.

В настоящей работе исследовалась электропроводность полимерных композитных структур на основе волокон хитозана, покрытых проводящим полимером полипирролом (ППир, Polypyrrole - РРу) как в сухом состоянии, так и в жидкой культуральной среде, имитирующей тканевую жидкость. Определены значения удельного сопротивления $\rho$ и проводимости $\sigma$ исследуемых волокон в зависимости от количества слоев ППир, степени вытяжки (ориентации) волокон в сухой и жидкой средах. Установлено, что с увеличением степени ориентации от 0 до $100 \% \rho$ волокон падает как в сухом состоянии, так и в жидкой культуральной среде. После этого резкого падения $\sigma$ ориентированных волокон хитозана с одним и двумя слоями ППир слабо меняется в жидкой культуральной среде.

\section{1. Материалы и методы исследований}

Для получения электропроводящих композиционных систем на основе хитозана и ППир использовали во- 
локна, полученные из хитозана фирмы „Biolog Нерре“ (Германия) с молекулярной массой $1.6-2.1 \cdot 10^{5}$ и степенью деацетилирования $92 \%$. Волокна формовали из $4 \%$ раствора хитозана в $2 \%$-ном растворе уксусной кислоты. Предварительно полученные растворы были отфильтрованы и обезвоздушены в течение $24 \mathrm{~h}$. Волокна формовали из раствора по мокрому (коагуляционному) методу, осадителем являлась спиртово-щелочная смесь, содержащая $10 \%$-й водный раствор $\mathrm{NaOH}$ и $\mathrm{C}_{2} \mathrm{H}_{5} \mathrm{OH}$ в соотношении $1: 1[7,8]$. Формование волокон проходило при следующих условиях: диаметр фильеры $0.6 \mathrm{~mm}$, скорость подачи раствора $0.2 \mathrm{ml} / \mathrm{min}$, время осаждения $150 \mathrm{~s}$, величина фильерной вытяжки $(\lambda)$ составляла 0,50 и $100 \%$. Полученные волокна промывали в дистиллированной воде, а затем сушили на воздухе при температуpe $50^{\circ} \mathrm{C}$. Слои ППир были сформированы на поверхности волокон хитозана методом окислительной полимеризации. В качестве окислителя использовали $1 \mathrm{M}$ раствор $\mathrm{FeCl}_{3} 6 \mathrm{H}_{2} \mathrm{O}$ в смеси метанол:вода $(1: 1)$. Полимеризацию пиррола проводили в газовой фазе мономера [6] следующим образом: исходные волокна выдерживали в растворе окислителя $1 \mathrm{~h}$, затем высушивали на воздухе при комнатной температуре. Обработанные окислителем волокна помещали в пары мономера. Время реакции полимеризации составляло $24 \mathrm{~h}$. Полученные композиционные волокна отмывали от остатков непрореагировавшего окислителя в метаноле. Для снижения растворимости и повышения прочности волокон хитозана в жидких средах проводилась их термическая модификация [9]. Для этого исходные волокна хитозана отжигали в муфельной печи в течение $5 \mathrm{~h}$ при температуре $120^{\circ} \mathrm{C}$. Полимеризацию пиррола на термически обработанных волокнах проводили по описанной выше схеме.

Для получения более однородного и равномерного слоя ППир на поверхности волокон был проведен повторный цикл полимеризации пиррола на предварительно полученных композиционных системах хитозан/ППир. Для этого волокна хитозана, покрытые ППир, снова погружали в раствор окислителя, а затем на сутки в пары мономера. Содержание ППир в композитах с однократным нанесением составляло $34 \%$ для волокон с вытяжкой $\lambda=0$ и $50 \%$ и $37 \%$ с $\lambda=100 \%$. Проведение повторной полимеризации пиррола привело к увеличению содержания ППир до $37 \%$ для волокон с $\lambda=0$ и $50 \%$ и до $39 \%$ с $\lambda=100 \%$. Структуры полимерных молекул хитозана и ППир представлены на рис. 1.

Морфология волокон хитозана, покрытых ППир, исследовались на сканирующем электронном микроскопе (СЭM) SUPRA 55VP, фирмы ZEISS (Германия). Образцы предварительно покрывались золотом $(\mathrm{Au})$ либо платиной $(\mathrm{Pt})$ методом катодного распыления $(15-20 \mathrm{~nm})$ на установке Quorum 150 (Великобритания) для обеспечения электропроводящих свойств исследуемых волокон и для исключения помех за счет накопления поверхностного заряда при сканировании, а также для повышения контрастности. Исследуемые волокна приклеивали двусторонним электропроводящим скотчем на столик
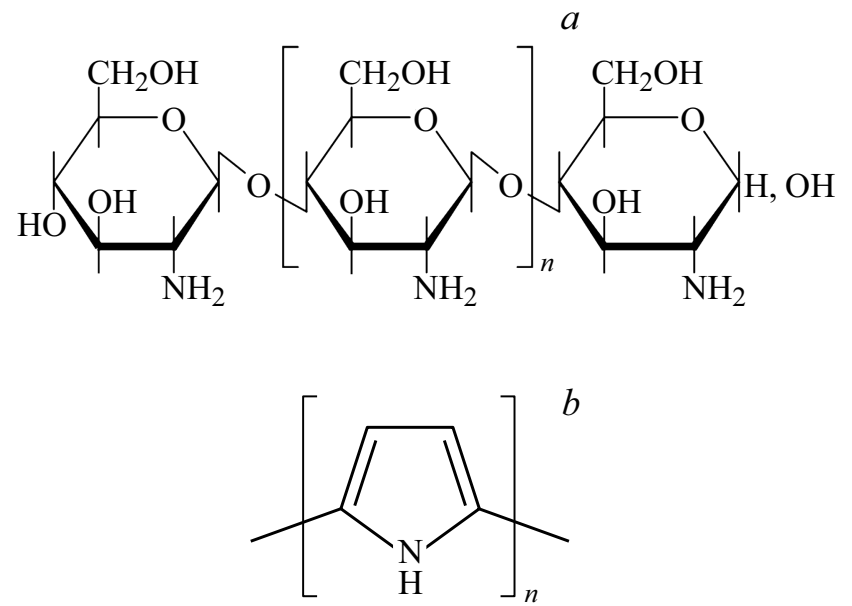

Рис. 1. Структуры полимерных молекул хитозана $(a)$ и ППир (b).

микроскопа. Для исследования морфологии поверхности использовался режим вторичных электронов (SE2).

Измерение электропроводности полимерных композитных волокон хитозана с ППир проводилось при комнатной температуре $(290 \mathrm{~K})$ с использованием автоматизированной установки для измерения вольтамперных характеристик (BAX) на основе пикоамперметра Keithley 6487 на постоянном токе в диапазоне напряжений от -10 до $+10 \mathrm{~V}$ (с шагом $1 \mathrm{~V}$ ). Контакты к образцам выполнялись углеродной пастой Conductive Carbon Paint фирмы SPI (дисперсность $-1 \mu \mathrm{m}$, удельное сопротивление $\left.-10^{-1} \Omega \mathrm{cm}\right)$, наносимой на торцы образцов волокон. Измерения ВАХ проводились в темноте и при освещении имитатором солнечного света для оценки фоточувствительности образцов; при прямом и обратном проходах для определения наличия гистерезиса ВАХ. Сопротивление волокон оценивалось из линейной части BAX при напряжении $+3-4 \mathrm{~V}$.

Были измерены BAX волокон хитозана с различной степенью вытяжки при их формировании (от 0 до 100\%) и с последующей их модификацией проводящим полимером ППир (покрытие волокон ППир в 1 и 2 слоя). Измерения ВАХ волокон проводились как в сухом состоянии, на воздухе, так и в жидкой культуральной среде, имитирующей тканевую среду, следующего состава: питательная среда DMEM (Панэко, Россия) с добавлением 1\% L-глютамина, $1 \%$ антибиотиков (100 units/ $\mu 1$ пенициллина, $100 \mu \mathrm{g} / \mathrm{ml}$ стрептомицина), $1 \%$ фунгизона $(25 \mu \mathrm{g} / \mathrm{ml}$ амфотерицин В), 10\% эмбриональной сыворотки телят (Gibco, CШA). При измерении BAX в культуральной среде при погружении образцов в жидкость контакты к волокнам оставались над поверхностью жидкой среды, таким образом, измерялось изменение сопротивления в жидкой среде только волокон хитозана со слоями ППир. Была исследована проводимость волокон хитозана с вытяжкой $\lambda=0,50$ и $100 \%$, покрытых 1 и 2 слоями ППир. 

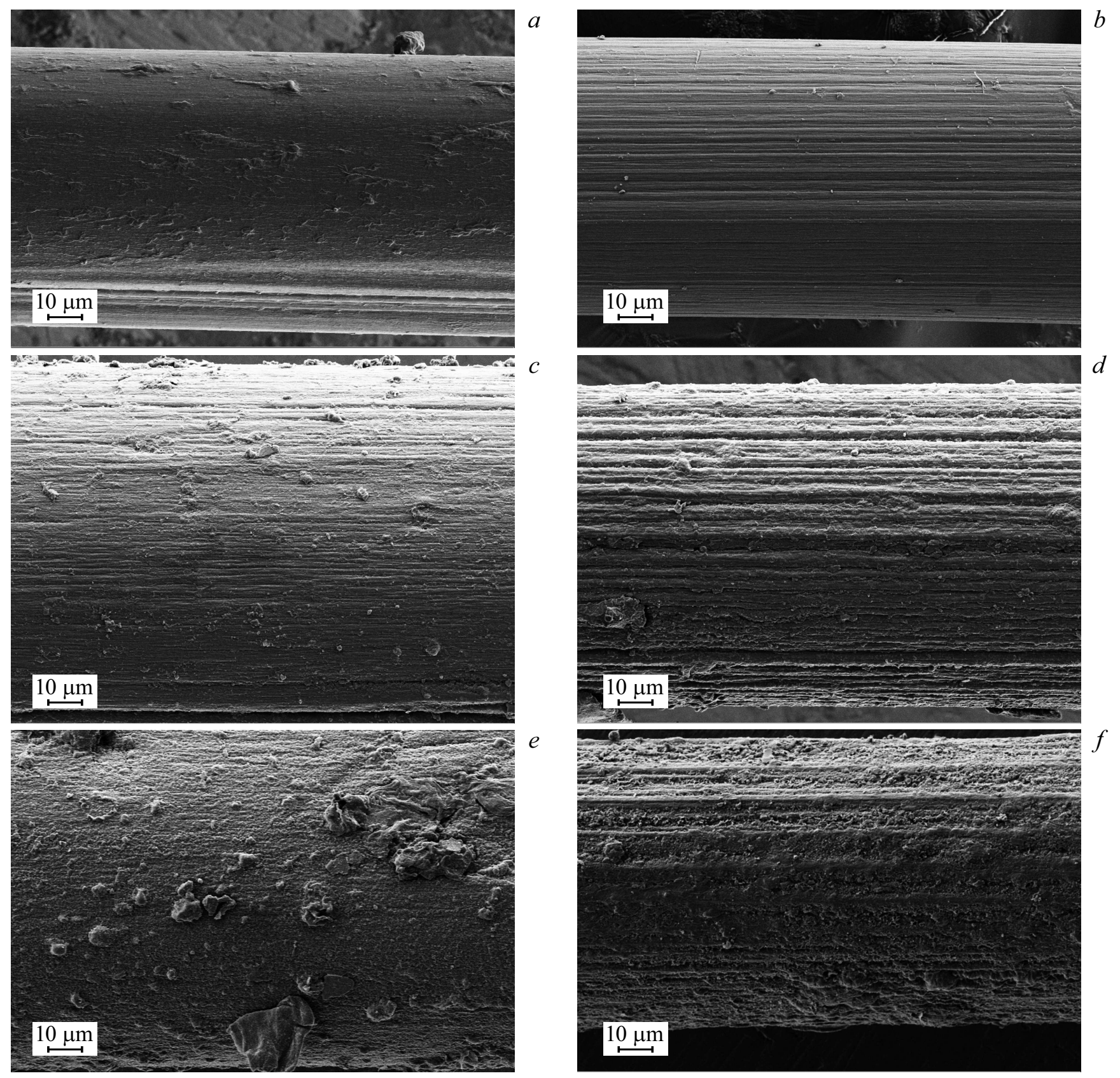

Рис. 2. Результаты СЭМ исследований морфологии волокон хитозана: $a$ - исходное хитозановое волокно $\lambda=0 \%$; $b-$ исходное хитозановое волокно, $\lambda=100 \% ; c-$ хитозановое волокно $\lambda=0 \%, 1$ слой ППир; $d-$ хитозановое волокно $\lambda=100 \%, 1$ слой ППир; $e-$ хитозановое волокно $\lambda=0 \%, 2$ слоя ППир; $f$ - хитозановое волокно $\lambda=100 \%, 2$ слоя ППир.

\section{2. Результаты и обсуждение}

На рис. 2 представлены результаты СЭМ исследований морфологии поверхности исходных волокон хитозана с $\lambda=0$ и $100 \%$, и композиционных волокон с 1 и 2 слоями ППир. Из рис. 2, $a, b$ видно, что для исходных волокон хитозана с ростом кратности фильерной вытяжки $\lambda$ на стадии формования наблюдается увеличение степени ориентации. Волокно с $\lambda=0 \%$ характеризуется слабоориентированной структурой, в то время как при $\lambda=100 \%$ наблюдается ярко выраженная фибриллярная структура с ориентацией в направлении вытяжки волокна. При нанесении 1 слоя ППир поверхность волокон становится более шероховатой и характеризуется морфологией, типичной для ППир (рис. 2,c). В то же время следует отметить, что формирующийся слой ППир наследует структуру поверхности волокна. На рис. 2, $d$ видно, что слой ППир, нанесенный на волокно хитозана с $\lambda=100 \%$, ориентирован вдоль фибрилл исходного волокна. Такая ориентация проводящего компонента вносит дополнительный вклад в увеличение проводимости композита. Проведение повторной поли- 
меризации пиррола приводит к увеличению содержания ППир в композите, о чем свидетельствует возрастающая толщина волокон от 80 до $119 \mu \mathrm{m}$ для композита, полученного на основе волокна хитозана с $\lambda=0 \%$ и от $70 \mu \mathrm{m}$ до $90 \mu \mathrm{m}$ для композита, на основе волокна хитозана с $\lambda=100 \%$. После двукратного нанесения ППир структура исходного волокна практически не просматривается, что свидетельствует об образовании равномерного и однородного слоя ППир по всей поверхности волокна. В то же время для композита, полученного на основе волокна хитозана с $\lambda=100 \%$, ориентация слоя ППир сохраняется. Как будет показано ниже, волокна с 100\% вытяжки и с 2 слоями ППир показывают максимальную проводимость в сухом состоянии.

На рис. 3 показаны ВАХ волокон хитозана, покрытых 1 и 2 слоями ППир, с вытяжкой 0, 50 и 100\%, измеренные в сухом состоянии при $290 \mathrm{~K}$ в прямом (рис. 3, $a$ ) и полулогарифмическом (рис. 3, $b$ ) масштабах. Как видно из рис. 3 , ВАХ всех образцов волокон в сухом состоянии имеют линейный характер при отсутствии гистерезиса, при этом максимальные значения тока (максимальная проводимость) были получены для сухих
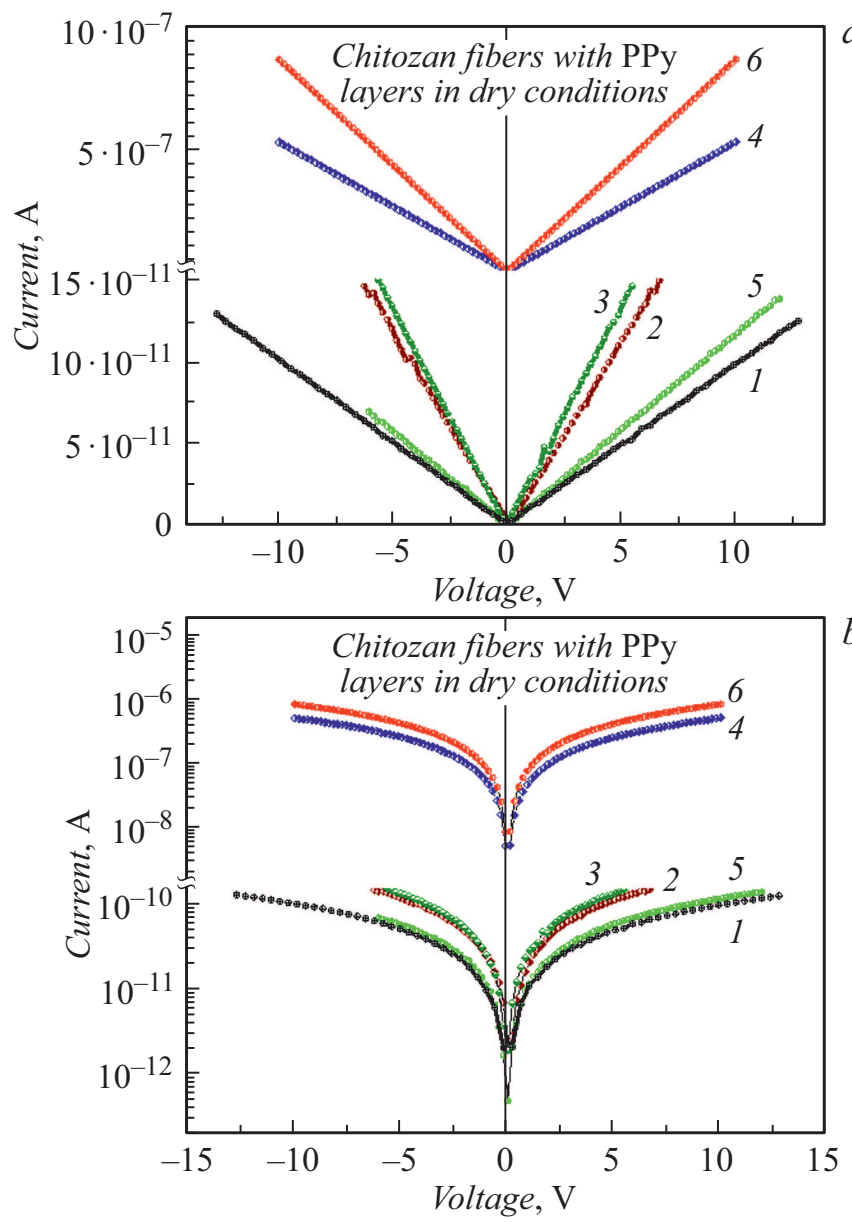

Рис. 3. ВАХ волокон хитозана, покрытых 1 и 2 слоями ППир, с вытяжкой $\lambda=0,50$ и $100 \%$, в сухом состоянии при $290 \mathrm{~K}$ в прямом $(a)$ и полулогарифмическом $(b)$ масштабах. Цифры соответствуют номерам образцов в таблице.

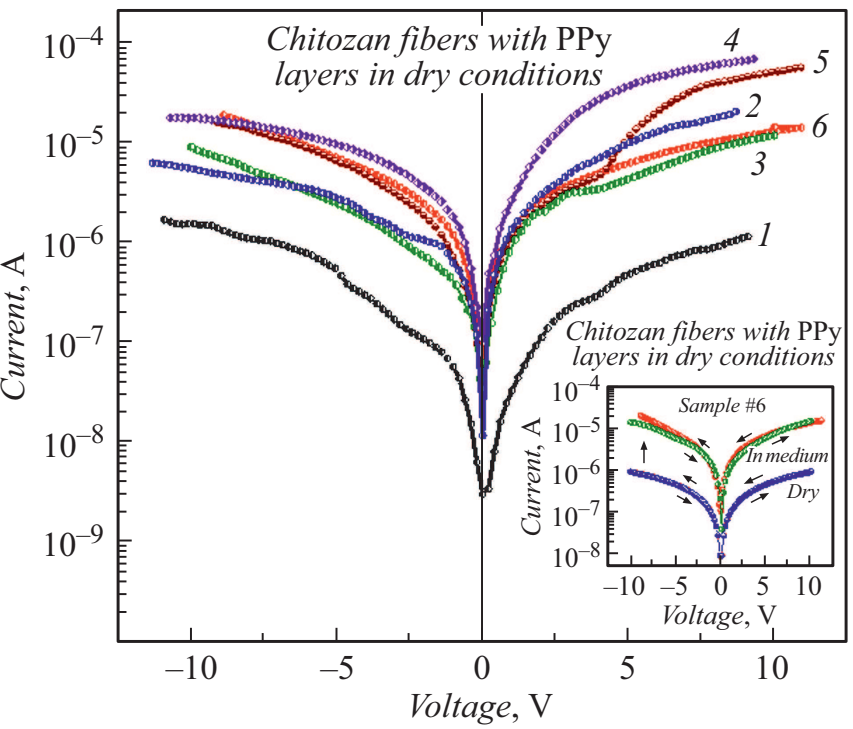

Рис. 4. ВАХ волокон хитозана, покрытых 1 и 2 слоями ППир, с вытяжкой 0, 50 и 100\%, погруженных в жидкую культуральную среду в полулогарифмическом масштабе при 290 К. Цифры соответствуют номерам образцов в таблице. На вставке: BAX образца № 6 в сухом состоянии и при погружении в жидкую среду при прямом и обратном проходе.

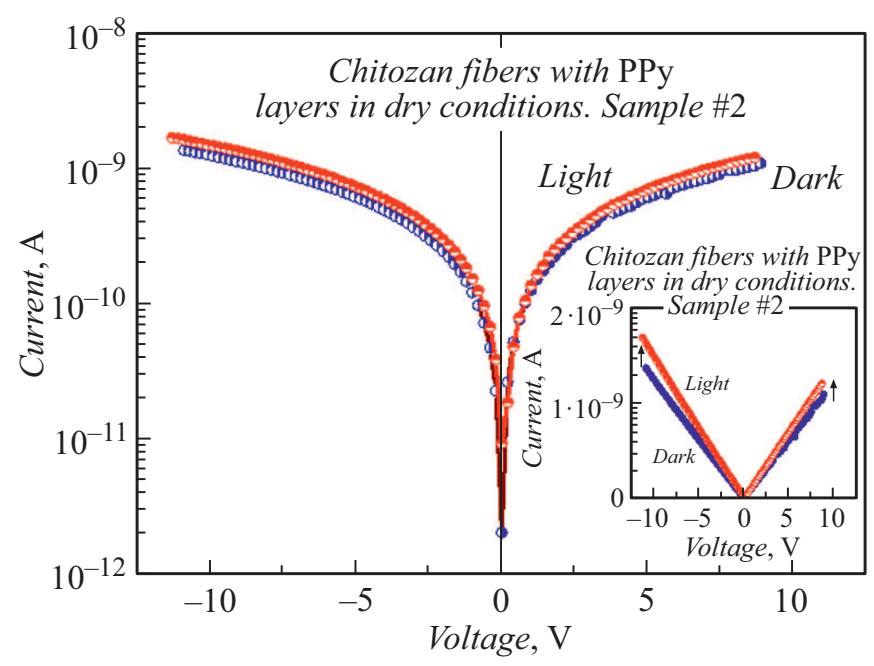

Рис. 5. ВАХ образца № 2 в сухом состоянии в темноте и при облучении волокон имитатором солнечного света в полулогарифмическом и прямом (на вставке) масштабах.

волокон с вытяжкой 50 и 100\% и с 2 слоями ППир. При погружении образцов волокон хитозана в жидкую культуральную среду наблюдался быстрый рост тока на 1-2 порядка для всех образцов (рис. 4). При этом в отличие от сухих образцов ВАХ образцов в жидкой среде имели заметный нелинейный характер с небольшим гистерезисом (вставка на рис. 4). При облучении образцов волокон имитатором солнечного света был обнаружен небольшой фототок (рис. 5), который превышал темновой ток в $1.3-1.5$ раза для неориентированных 
Значения удельного сопротивления и проводимости волокон хитозана, покрытых ППир

\begin{tabular}{c|c|c|c|c|c|c|c|c}
\hline \multirow{2}{*}{$\begin{array}{c}\text { Номер } \\
\text { образца }\end{array}$} & \multirow{2}{*}{$\begin{array}{c}\text { Вытяжка, } \\
\lambda, \%\end{array}$} & \multirow{2}{*}{$\begin{array}{c}\text { Количество } \\
\text { слоев ППир }\end{array}$} & \multicolumn{3}{|c|}{ В сухом состоянии } & \multicolumn{3}{|c}{ В жидкой среде } \\
\cline { 4 - 9 } & & & $R, \Omega$ & $\rho, \Omega \mathrm{cm}$ & $\sigma, \mathrm{S} / \mathrm{cm}$ & $R, \Omega$ & $\rho, \Omega \mathrm{cm}$ & $\sigma, \mathrm{S} / \mathrm{cm}$ \\
\hline 1 & 0 & 1 & $1.2 \cdot 10^{11}$ & $3.2 \cdot 10^{6}$ & $3.10 \cdot 10^{-7}$ & $6.35 \cdot 10^{6}$ & 166.31 & 0.006 \\
2 & 0 & 2 & $3.79 \cdot 10^{10}$ & $1.29 \cdot 10^{6}$ & $7.74 \cdot 10^{-7}$ & $1.49 \cdot 10^{6}$ & 50.53 & 0.0197 \\
3 & 50 & 1 & $9.55 \cdot 10^{10}$ & $1.97 \cdot 10^{6}$ & $5.07 \cdot 10^{-7}$ & $1.12 \cdot 10^{6}$ & 22.98 & 0.0435 \\
4 & 50 & 2 & $1.9 \cdot 10^{7}$ & $4.41 \cdot 10^{2}$ & $2.2 \cdot 10^{-3}$ & $4.64 \cdot 10^{5}$ & 10.78 & 0.0928 \\
5 & 100 & 1 & $3.0 \cdot 10^{11}$ & $5.82 \cdot 10^{6}$ & $1.72 \cdot 10^{-7}$ & $9.38 \cdot 10^{5}$ & 18.16 & 0.055 \\
6 & 100 & 2 & $1.2 \cdot 10^{7}$ & $1.59 \cdot 10^{2}$ & $6.3 \cdot 10^{-3}$ & $9.19 \cdot 10^{5}$ & 12.57 & 0.0795
\end{tabular}

Приме чание. Отжиг волокон хитозана перед нанесением ППир -5 h.

волокон хитозана, покрытых ППир. Еще более слабый фотоотклик наблюдался у ориентированных (50, 100\%) волокон хитозана, покрытых 1 и 2 слоями ППир, из чего следует, что проводимость таких волокон практически не меняется при освещении, что важно при проведении операций тканевой инженерии с такими материалами. Значения $\rho$ и проводимости $\sigma=1 / \rho$ волокон хитозана с различной вытяжкой, покрытых 1 и 2 слоями ППир, в сухом состоянии и в жидкой культуральной среде представлены в таблице. (Цифры на рисунках соответствуют номерам образцов в таблице.)

Зависимости $\rho$ образцов с 1 и 2 слоями ППир от степени вытяжки на воздухе и в жидкой культуральной среде показаны на рис. 6. Как следует из рис. 6, для большинства образцов (кроме неориентированного образца № 1, покрытого 1 слоем ППир) величина $\rho$ падает с увеличением степени вытяжки образцов от 0 до $100 \%$ как в сухом состоянии, так и в жидкой среде. Однако если для сухих волокон отношение $\rho / \rho_{0}$ составляет 4 порядка величины для волокон с двумя слоями ППир, то во влажной культуральной среде это отношение не превышает 4.5. При этом максимальное падение $\rho$ (рост $\sigma$ ) волокон при погружении в жидкую культуральную среду наблюдалось для неориентированных волокон

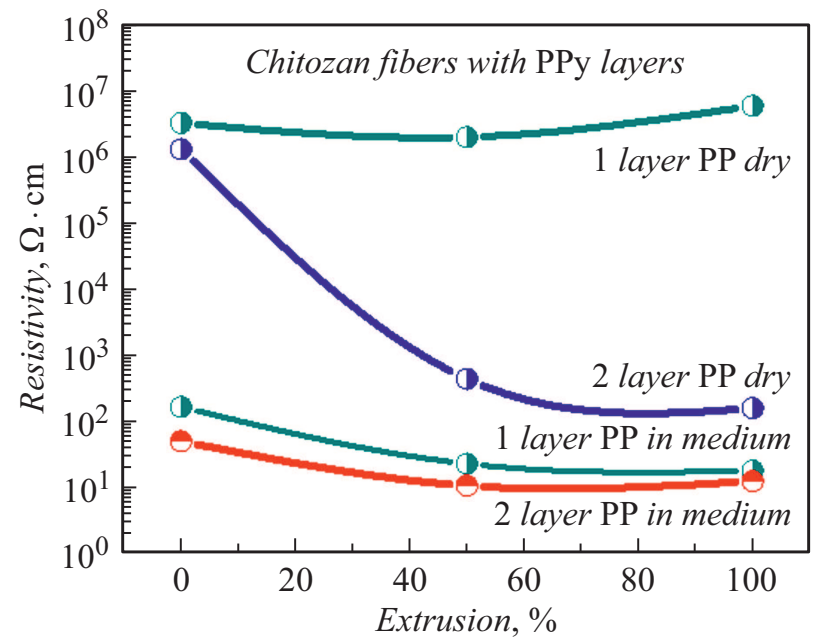

Рис. 6. Зависимости удельного сопротивления $\rho$ образцов волокон с 1 и 2 слоями ППир от степени вытяжки в сухом состоянии и в жидкой культуральной среде.

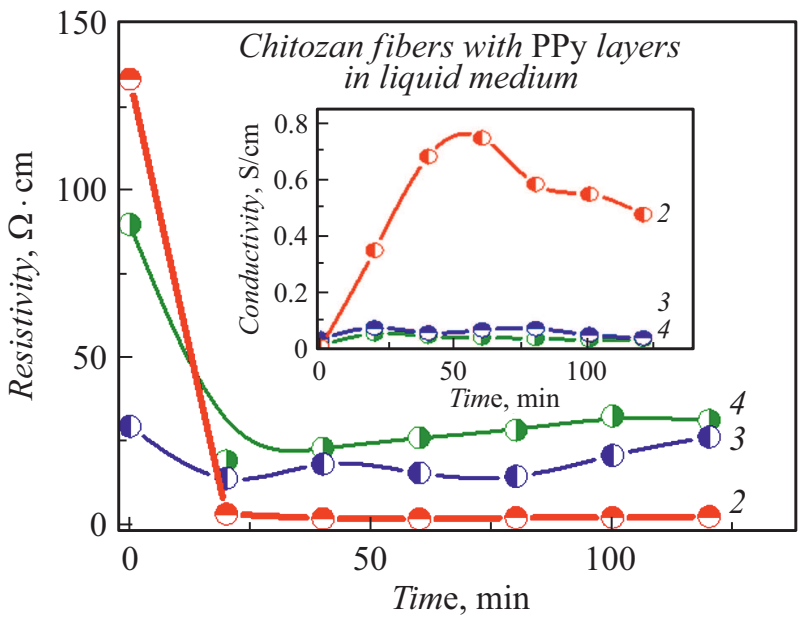

Рис. 7. Зависимости удельного сопротивления $\rho$ и проводимости (на вставке) образцов волокон от времени выдержки в жидкой культуральной среде. Цифры соответствуют номерам образцов в таблице.

(вытяжка 0\%) с двумя слоями ППир. Значения $\rho$ образцов волокон, покрытых ППир, оставались стабильными при измерении в сухом состоянии, однако они менялись во времени при погружении волокон в жидкую среду. Зависимости $\rho$ и проводимости образцов волокон от времени нахождения их в жидкой среде показаны на рис. 7. Как следует из рис. 7, наибольшие изменения проводимости волокон при их выдержке в жидкой среде наблюдаются в неориентированных волокнах. В то же время наименьшие изменения $\rho$ и проводимости волокон при погружении их в жидкую культуральную среду наблюдались для образцов с вытяжкой 50-100\%, покрытых 1-2 слоями ППир. Такие волокна, по нашему мнению, можно рассматривать как наиболее перспективные для создания приборов тканевой инженерии.

\section{Заключение}

Синтезированы полимерные композитные структуры на основе ориентированных волокон хитозана, покрытых проводящим полимером ППир, и исследована их морфология методом СЭМ. Исследована электропроводность 
волокон хитозана со слоями ППир как в сухом состоянии, так и в жидкой культуральной среде, имитирующей тканевую жидкость. Определены значения $\rho$ и $\sigma$ исследуемых волокон в зависимости от количества слоев ППир, степени вытяжки (ориентации) волокон в сухой и в жидкой средах. Установлено, что с увеличением степени ориентации от 0 до $100 \% \rho$ волокон падает как в сухом состоянии, так и в жидкой культуральной среде, при этом максимальное падение $\rho$ при погружении волокон в жидкую среду наблюдалось для неориентированных волокон с двумя слоями ППир. После начального падения $\rho$ ориентированных волокон хитозана с 1 и 2 слоями ППир $\rho$ слабо меняется в жидкой среде в течение $2 \mathrm{~h}$. Полимерные электропроводящие волокна хитозана со степенью вытяжки 50 и 100\%, покрытые 1 и 2 слоями ППир, перспективны для создания приборов в области тканевой инженерии.

\section{Благодарности}

Работа выполнена при поддержке гранта РНФ 19-7330003.

\section{Конфликт интересов}

Авторы заявляют, что у них нет конфликта интересов.

\section{Список литературы}

[1] M.Z. Albanna, T.H. Boi-Akl, O. Blowytsky, H.L. Walters III, H.W.T. Matthew. J. Mechan. Behavior of Biomed. Mater., 20, 217 (2013). DOI: 10.1016/j.jmbbm.2012.09.012

[2] P. Moutsatsou, K. Coopman, S. Georgiadou. Polymers, 9, 687 (2017). DOI: 10.3390/polym9120687

[3] H. Qin, J. Li, B. He, J. Sun, L. Li, L. Qian. Materials, 11, 370 (2018). DOI: 10.3390/ma11030370

[4] J.D. Kendall, S. Kumar. Appl. Phys. Rev., 7, 011305 (2020). https://doi.org/10.1063/1.5129306

[5] A.N. Aleshin. Adv. Mater., 18, 17 (2006). https://doi.org/10.1002/adma.200500928

[6] E. Dresvyanina, E. Rosova, N. Smirnova, E. Ivan'kova, O. Moskalyuk, I. Dobrovolskaya, V. Elokhovskiy, A. Aleshin, V. Yudin. Textile Res. J. (2021).

DOI: http://dx.doi.org/10.1177/00405175211006217

[7] Е.Н. Маевская, Е.Н. Дресвянина, А.Н. Юденко, В.Е. Юдин. ЖТФ, 88 (9), 1366 (2018).

DOI: $10.21883 /$ JTF.2018.09.46422.15-18

[8] E. Dresvyanina, A. Yudenko, N. Yevlampieva, E. Maevskaya, V. Yudin, A. Gubarev, M. Slyusarenko, K. Heppe. FIBRES aTEXTILES, 25, 27 (2018).

[9] М.А. Зоткин, Г.А. Вихорева, А.С. Кечекьян. Высокомол. соед. Б, 46, 359 (2004). 